\title{
PRESENTING A LITERATURE REVIEW WITH INFOGRAPHICS: CREATIVITY COMPETENCE FOR MASTER STUDENTS
}

\author{
María de-Miguel-Molina, Virginia Santamarina-Campos, Blanca de-Miguel- \\ Molina, María-Ángeles Carabal-Montagud, Daniel Catalá-Pérez \\ Universitat Politècnica de València (SPAIN)
}

\begin{abstract}
In this work we present the results of encouraging creativity in a Master subject where its thematic, research methodologies, could be sometimes quite academic for the students. The first objective in this experience was to apply a STEAM competence, Science, by means of giving freedom to the students to select a topic of interest and create research questions about it. The second objective, one the literature review was developed, was to apply a second STEAM competence, Arts \& Design, using a digital tool for representing their analysis in a creative way. For doing so, we decided to present them different infographic open applications that help them to represent their study. But again, we did not provide a compulsory template or graphic, letting them to explore the tool and to select the way of representing their results. As we observed, the level of creativity was different depending on the student but all of them made the effort to use the tool. Moreover, we suggested a second tool, the visualization of literature maps with software tools, in order to explore future research gaps of interest. At the end of the experience, we delivered a questionnaire to the students to review all the STEAM competences, including creativity within Science and Arts \& Design.
\end{abstract}

Keywords: infographic, STEAM competences, creativity, literature review, literature map, master level.

\section{INTRODUCTION}

The work that we present is developed within two educational innovation and improvement projects of the Universitat Politècnica de València (UPV). They are composed by professors from two departments, Management and Conservation \& Restoration of Cultural Heritage, to achieve synergies that allow us to cover all STEAM strategies. In the first project, "Applying STEAM strategies in the areas of Social Sciences and Art", we propose in our subjects the development of Science, Technology, Enginnering, Arts \& Design and Maths competences. In this case, we have focused on: being able to establish research questions/hypotheses (Science competence) and to propose creative solutions (Arts \& Design competence). In the second project, "Infographics. Use of Information and Communication Technologies (ICT) in the visual and creative representation of content for teaching", the aim is that the students would be able to synthesize contents and to represent them through infographics, with free and open software.

In the UPV, the Arts \& Design competence is often absent from the subjects that do not belong to the field of Fine Arts [1], so its incorporation leads us to the development of STEAM competences, going beyond the purely technological or scientific ones [2]. Roberts [3] already highlighted the need to promote creative programs, aimed at helping young people to find paths to the creative industries. Moreover, studying at a technical university can give greater value to their curricula [4].

The aim of the subject "Research Methodologies" is to introduce the students the basics of research methods for the social sciences to assist them in developing their Master's Thesis. For achieving this goal, we cover these specific education objectives:

- Learn how to use some bibliography software while reviewing the literature.

- Find a subject of academic research/knowledge contribution.

- Differentiate qualitative \& quantitative research methods.

- Develop research with and for communities, seeking for sustainable development goals.

From them, some student outcomes are expected: 
- To acquire and understand the sufficient knowledge for having the basis and opportunities to develop and apply innovative ideas, within a research context.

- To acquire the pertinent learning skills to continue studying in a self-guided and autonomous way.

- To propose, analyse, validate and interpret solutions in real situations within the different company's areas.

Moreover, the activities proposed for covering generic student outcomes are:

- Comprehension and integration: The student must present a protocol whose topic will be developed with the supervisor. The student will plan the final work of the subject with this protocol.

- Critical thinking: The student will propose, discuss and draw conclusions from the tasks developed along the course, including evidences with the use of technology.

- Specific tools: The student must present an academic review whose topic will be developed with the supervisor. The student will collect a reference list of around 20 references on a particular subject to present a short review. Key points are:

a) propose innovative and relevant topics.

b) work with autonomy, based on the objectives proposed.

c) present an original analysis.

d) propose a future research goal.

As we can see, to be innovative is encouraged by the subject outlines, but we wanted to go further and apply a creative tool that let them to explain a conceptual work in something very specific such an image.

\section{METHODOLOGY}

The experience was developed in four phases. Two of the assignments were compulsory and the third one was elective for the students. In the first step, the Science competence (S) was applied [5] and the students should develop a protocol proposing research questions around any topic of interest. According to Feldt [6], a research question (RQ) is a question that your study sets out to answer and it must be accurately and clearly defined.

In the second step, the Arts \& Design competence (A) was applied, asking them to create an infographic from their literature review. The use of infographics lets to optimize the knowledge process, based on a smaller quantity and greater precision of the information. A good infographic should:

- Allow to process the information in less time and effort than through other means.

- Be attractive and impressive.

- Be reliable. The information presented must be true.

- Concentrate the most relevant information that we want to communicate.

For creating the infographics, we proposed different open software tools, such as Piktochart or Easel.ly. All these platforms provide templates than can help them to represent the information. We provided them two examples to see how the same info could be represented highlighting different aspects, in this case the interrelations (Figure 1) or the timeline (Figure 2), but they could choose other point, for instance the geographical (placing the items in a map). 


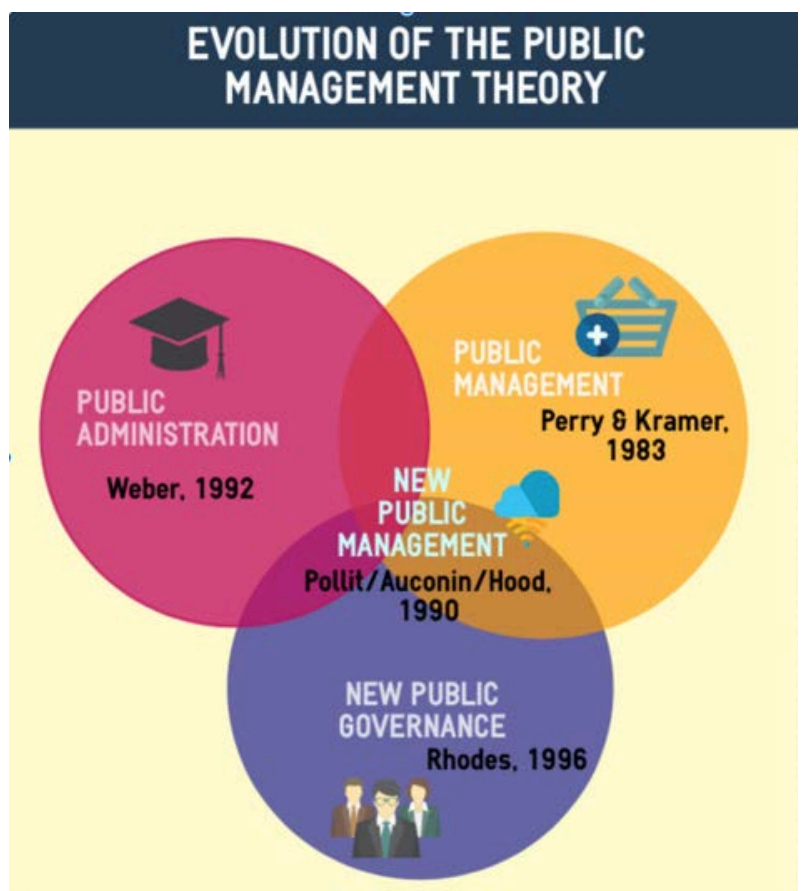

Figure 1. Example of infographic based on the interrelations among theory paradigms (own elaboration with Easel.ly).

In Figure 2 we used Xmind that, although it is focused on mind maps, has also some tools to create different graphics.

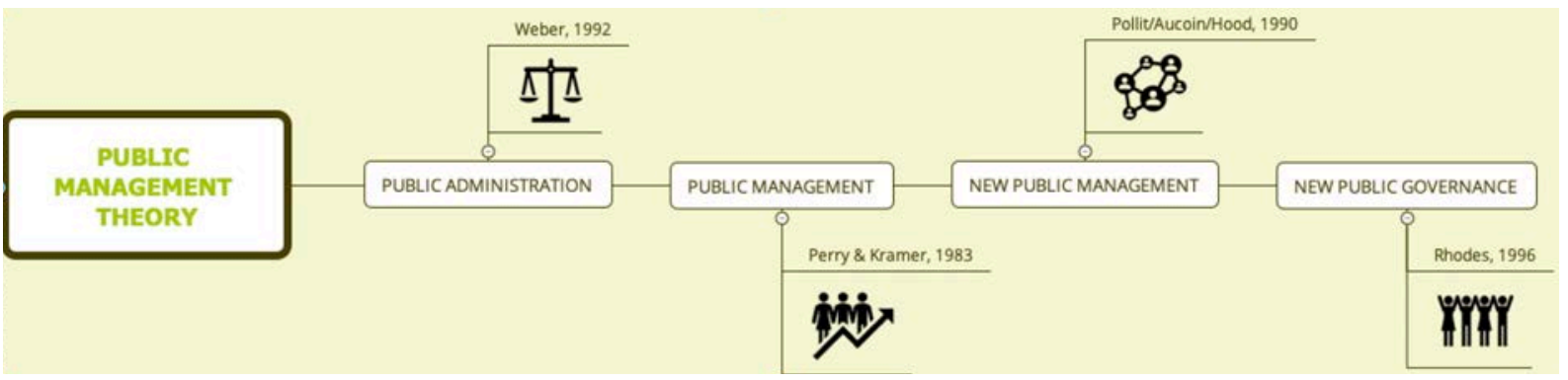

Figure 2. Example of infographic based on the timeline of theory paradigms (own elaboration with Xmind).

In the third step, who was a voluntary assignment, we suggested them to create a visual literature map with their references, collected through Scopus, in order to check the co-ocurrences among the different keywords and identify future research gaps. For this part, they could also select different open software tools, such as VosViewer or AtlasTi.

In the last stage, a questionnaire regarding the STEAM competences was delivered (Figure 3). This questionnaire had been checked previously by the STEAM project members. It was provided to the students in-person, so that we were with them to solve doubts. 


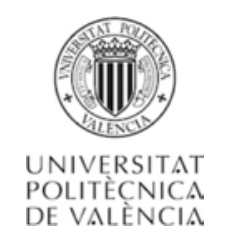

\section{STEAM}

INNOVATION AND EDUCATIONAL IMPROVEMENT PROJECT

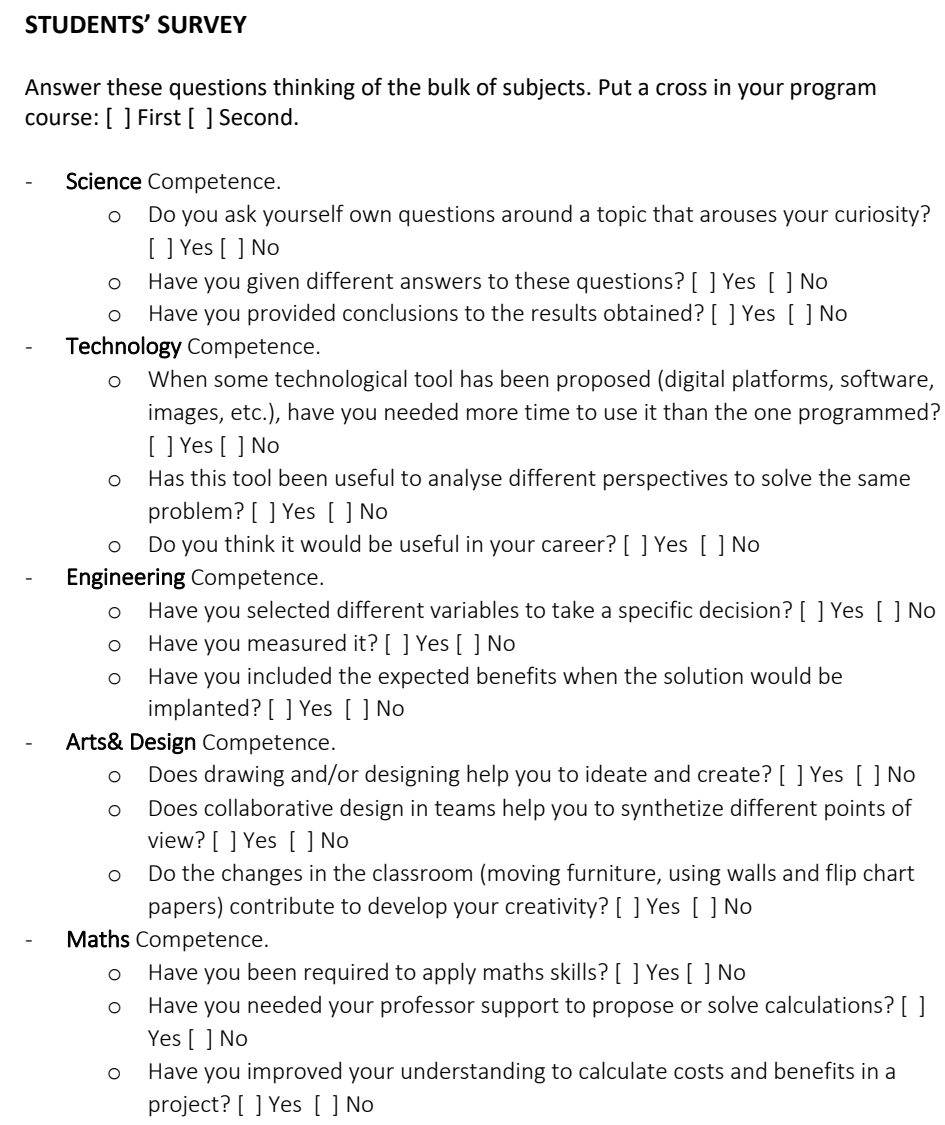

* The Project STEAM, coordinated by Professor María de Miguel, is compound by professors from the Faculty of Business Administration and the Faculty of Fine Arts, and its objective is that the students will be able to apply STEAM strategies (Science, Technology, Engineering, Art\&Design, Maths) in order to develop Service-Learning outside activities that could be applied in the community.

Figure 3. STEAM questionnaire for Master students (own elaboration).

\section{RESULTS}

The first assignment was completed by all the students, they were able to provide research questions for a topic of their interest. For this subject, the students' RQs are mainly Exploratory. Therefore, they can be [7]:

- Existence: "Does X exist?", "Has coronavirus reduced the cities pollution?"

- Descriptive: "What is X like?", "What are microalgae food properties/attributes?", "How can we categorize/measure a company green image?", "What are the components of agile methodology?"

- Comparative: "How does a traditional music promotion differ from an artist own promotion?"

The second assignment was also accomplished, with different ways of representation, more or less creative. Some students were able to provide the most important information with the image, while for others it was more difficult and maybe the figures were too simple. 
The third assignment, that was voluntary, was presented only by few students. Anyway, as all of them presented their works in the classroom, their classmates could see the potential of the tool. We provided also an example [8] to show the possibilities of the software, in this case VosViewer (Figure 4):

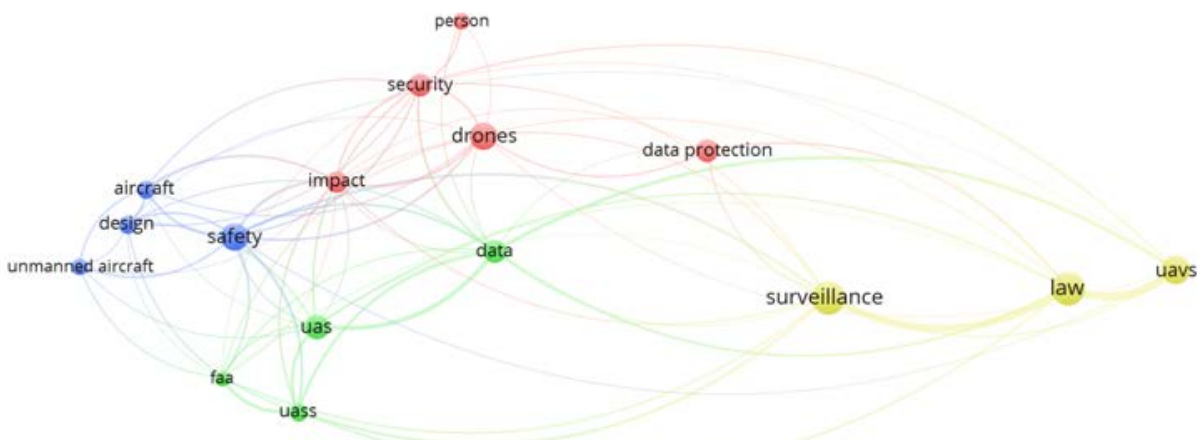

Figure 4. VosViewer visualization from [8] (own elaboration).

Finally, the questionnaire was provided and, as we can observe in Table 1, both competences were covered with this activity. To the question "Do you ask yourself own questions around a topic that arouses your curiosity?", all of them agreed. And for the question, "Does drawing and/or designing help you to ideate and create?", $93 \%$ of the students agreed.

Moreover, it is also interesting to pay attention to the Technology competence. Even if $64 \%$ of the students think that the technological tools proposed have needed more time to learn, they are useful to analyse different perspectives for solving the same problem and they would be useful in their career [9].

Table 1. Results of the STEAM questionnaire (own elaboration).

\begin{tabular}{|c|c|c|c|}
\hline COMPETENCE & QUESTIONS & YES & NO \\
\hline \multirow[t]{3}{*}{ Science } & $\begin{array}{l}\text { Do you ask yourself own questions around a topic that arouses your } \\
\text { curiosity? }\end{array}$ & $100 \%$ & \\
\hline & Have you given different answers to these questions? & $50 \%$ & $50 \%$ \\
\hline & Have you provided conclusions to the results obtained? & $57 \%$ & $43 \%$ \\
\hline \multirow[t]{3}{*}{ Technology } & $\begin{array}{l}\text { When some technological tool has been proposed (digital platforms, } \\
\text { software, images, etc.), have you needed more time to use it than the } \\
\text { one programmed? }\end{array}$ & $64 \%$ & $36 \%$ \\
\hline & $\begin{array}{l}\text { Has this tool been useful to analyse different perspectives to solve the } \\
\text { same problem? }\end{array}$ & $100 \%$ & \\
\hline & Do you think it would be useful in your career? & $100 \%$ & \\
\hline \multirow[t]{3}{*}{ Engineering } & Have you selected different variables to take a specific decision? & $93 \%$ & $7 \%$ \\
\hline & Have you measured it? & $78,5 \%$ & $21,5 \%$ \\
\hline & $\begin{array}{l}\text { Have you included the expected benefits when the solution would be } \\
\text { implanted? }\end{array}$ & $93 \%$ & $7 \%$ \\
\hline \multirow[t]{3}{*}{ Arts\&Design } & Does drawing and/or designing help you to ideate and create? & $93 \%$ & $7 \%$ \\
\hline & $\begin{array}{l}\text { Does collaborative design in teams help you to synthetize different } \\
\text { points of view? }\end{array}$ & $78,5 \%$ & $21,5 \%$ \\
\hline & $\begin{array}{l}\text { Do the changes in the classroom (moving furniture, using walls and flip } \\
\text { chart papers) contribute to develop your creativity? }\end{array}$ & $78,5 \%$ & $21,5 \%$ \\
\hline \multirow[t]{3}{*}{ Maths } & Have you been required to apply maths skills? & $78,5 \%$ & $21,5 \%$ \\
\hline & Have you needed your professor support to propose or solve calculations? & $28,5 \%$ & $71,5 \%$ \\
\hline & $\begin{array}{l}\text { Have you improved your understanding to calculate costs and benefits in } \\
\text { a project? }\end{array}$ & $71,5 \%$ & $28,5 \%$ \\
\hline
\end{tabular}




\section{CONCLUSIONS}

Working the STEAM competences is not always easy, depending on the subject. Our challenge was to integrate Science and Arts \& Design in a subject on research methodologies, and we managed to do it through the use of infographics. This is the result of our collaboration in a multidisciplinary team, where we create a lot of synergies between arts and management.

Anyway, in the future we could improve these competences more. Our university (UPV), has been evaluating, since the last years, different transversal skills [10] and, recently, it has also incorporated the Sustainable Development Goals (SDGs) [11]. In our STEAM project, we have related all of them as we think that STEAM competences are easier to understand for the students. In our Master Programs, we observe that we have still some of them to cover [8], so it would be convenient to complete them through new practices and activities. Specifically, we observed that the cross-sectional competence UPV 5 (Design and project) is not enhanced and it could be related to $S$ (Science).

As for the SDGs that are not covered, they could be related to A (Arts \& Design). Particularly, taking into account the importance of contributing with innovative and creative ideas, the SDGs could be: SDG 1. End poverty in all its forms everywhere, SDG 3. Ensure healthy lives and promote well-being for all in all ages, SDG 4. Ensure inclusive, equitable and quality education and promote lifelong learning opportunities for all, SDG 5. Achieve gender equality and empower all women and girls, SDG 8 . Foster sustained, inclusive and sustainable economic growth, full and productive employment, and decent work for all, SDG 10. Reduce inequality within and between countries, SDG 16. Promote just, peaceful and inclusive societies, SDG 17. Revitalize the World Alliance for Sustainable Development. And for example, in the case of this subject, in the next years it could be a challenge to start from the SDGs to choose a topic of interest.

In short, we observe the importance of STEAM strategies to achieve a more complete and creative training for our students and, nowadays, we can find a lot of open and free software tools to accomplish it.

\section{ACKNOWLEDGEMENTS}

This work has been developed within the projects "Applying STEAM strategies in the Social Sciences and Arts areas by means of a Service-learning methodology", conducted by Professor María de-MiguelMolina, and "Infographics. Use of Information and Communication Technologies (ICT) in the visual and creative representation of content for teaching", conducted by Professor María-Ángeles CarabalMontagud. Both projects are developed with the support of the Universitat Politécnica de València (Science Education Institute, ICE).

\section{REFERENCES}

[1] V. Santamarina-Campos, M. De-Miguel-Molina, B. De-Miguel-Molina, M.A. Carabal-Montagud, "Art Thinking as a catalyst for STEAM strategies. Towards a divergent thinking", 14th International Technology, Education and Development Conference (INTED), 766-774, 2020.

[2] M. De-Miguel-Molina, D. Catalá-Pérez, A. Peiró Signes, M.V. Segarra-Oña, "STEAM education at Master level", 14th International Technology, Education and Development Conference (INTED), 1260-1264, 2020.

[3] P. Roberts, Nurturing Creativity in Young People: A report to Government to inform future policy. United Kingdom: Department for Culture, Media and Sports, 2006.

[4] Innobasque, ¿De qué hablamos cuando hablamos de STEAM?, Accessed 25 July, 2020. Retrieved from https://www.innobasque.eus/microsite/escuela_innovacion/article/de-que-hablamos-cuandohablamos-de-steam/

[5] B. De-Miguel-Molina, M. de-Miguel-Molina, M.V. Segarra-Oña, V. Santamarina-Campos, "Encouraging curiosity through STEAM strategies: incorporating the Science competence into the Social Sciences field", 13th International Conference of Education, Research and Innovation (ICERI 2020), 4754-4759, 2020.

[6] R. Feldt, Guide to research questions, 2010, Retrieved from http://www.cse.chalmers.se/ feldt/advice/guide_to_creating_research_questions.pdf 
[7] J. Meltzoff, Critical Thinking About Research: Psychology and Related Fields. Washington DC: American Psychological Association, 1998.

[8] M. de-Miguel-Molina, V. Santamarina-Campos, M.A. Carabal Montagud, B. de-Miguel-Molina, "Ethics for civil indoor drones: A qualitative analysis", International Journal of Micro Air Vehicles, 340-351, 2018, doi: https://doi.org/10.1177/1756829318794004

[9] M. de-Miguel-Molina, M.A. Carabal-Montagud, D. Catalá-Párez, A. Peiró-Signes, "Integrando competencias STEAM: la fotografía como nexo entre la ciencia y la tecnología en las ciencias sociales", XI Congreso Iberoamericano de Docencia Universitaria (CIDU), 2021.

[10] Universitat Politècnica de València, Competencias Transversales, Accessed 10 July, 2020. Retrieved from http://www.upv.es/contenidos/COMPTRAN/index-en.html

[11] United Nations, Sustainable Development Goals, Accessed 10 July, 2020. Retrieved from https://www.un.org/sustainabledevelopment/ 